\title{
Sea-ice roughness and drag coefficients in a dynamic-thermodynamic sea-ice model for the Arctic
}

\author{
By NADJA STEINER*, MARKUS HARDER and PETER LEMKE, Institut für Meereskunde Kiel, \\ Düsternbrooker Weg 20, 24105 Kiel, Germany
}

(Manuscript received 14 September 1998; in final form 11 June 1999)

\section{ABSTRACT}

A quantitative relationship between observed sea-ice roughness and simulated large-scale deformation work is established in order to provide new means for model validation and a better representation of the sea-ice component in climate modelling. Sea-ice roughness is introduced as an additional prognostic variable in a dynamic-thermodynamic sea-ice model with a viscous-plastic rheology. It is defined as the accumulated work of internal forces acting upon an ice volume, given in energy per area. A fraction of this total deformation work is transferred to the potential energy stored in pressure ridges. Using ridge geometries and distribution functions from observations, observable quantities like mean pressure ridge height, ridge frequency as well as volumetric and areal fractions of deformed ice are derived from the simulated ice roughness. Comparisons of these simulated quantities with measurements (submarine-borne sonars, laser altimeters on helicopters) show good agreement. Satellite-borne observations of sea-ice roughness now under development will provide an even larger data set which will be used for model verification. Additionally roughness-dependent drag coefficients are introduced to account for the effect on the momentum exchange between ocean and atmosphere due to the form drag of roughness elements. The simulations indicate that the inclusion of sea-ice roughness provides for a more realistic representation of the boundary layer processes in climate models.

\section{Introduction}

Winds are the primary driving force of ice motion in the Arctic (Thorndike and Colony, 1982; Hilmer et al., 1998). The resulting ice drift causes compression and deformation of sea-ice in areas of convergence and shearing. The subsequent internal forces perform deformation work on the ice cover, which is partially transformed into potential energy stored in pressure ridges while the remainder is transformed into plastic deformation and work due to friction (Rothrock, 1975). The regional distribution of pressure ridges gives

* Corresponding author. e-mail: nsteiner@ifm.uni-kiel.de information on the intensity and frequency of deformation processes and is a measure of sea-ice roughness. Measurements of laser altimeters from aircrafts and helicopters are so far the most common method to obtain the surface topography over larger regions (Wadhams, 1980; Dierking, 1995; Haas and Lensu, 1997), and submarineborne sonars supply appropriate measurements of spatial distribution of the ice draft (Bourke and McLaren, 1992; Wadhams, 1994; Davis and Wadhams, 1995). Satellite-borne measurements from active microwave radiometers over ice are an encouraging alternative of long-term and largescale observations of the surface roughness (Carlström and Ulander, 1995; Dierking et al., 1997; Liu et al., 1998; Haas et al., 1998a,b). The 
available roughness measurements suggest the utilization of sea-ice roughness which also contains information about the vertical ice structure to supplement the sparse ice thickness data (Steiner et al., 1998a,b; Steiner, 1999). The calculation of sea-ice roughness in large-scale ice models enables the validation of the ice rheology as well as an estimation of the influence that rough ice has on dynamic and thermodynamic processes. Models with different ice classes for individual ice types are a first attempt to consider the different physical behaviour of deformed and nondeformed ice (Leppäranta, 1981; Flato and Hibler, 1991; Harder and Lemke, 1994). But these models are not yet able to describe the conversion between ice classes accurately, due to the manifold physical processes which are involved. The introduction of sea-ice roughness as a prognostic variable (Harder, 1996, 1997) pays regard to deformation processes without considering individual ridge formations. Thorndike (1992) avoids the examination of detailed deformation processes in a similar manner by using a redistribution function to calculate draft distributions. This paper describes the development and validation of a parameterization scheme to transform simulated large-scale deformation work into quantities which can also be derived from in situ measurements like pressure ridge distributions or volumetric and areal fractions of deformed ice.

The introduction of roughness-dependent drag coefficients pays regard to the properties of the ice-ocean and ice-atmosphere interactions related to the differences between strongly deformed and barely deformed ice, e.g., Andreas (1995) suggests from model studies that form drag may account for up to $80 \%$ of the surface stress. In present-day sea-ice models only constant drag coefficients are used, which represent mean values over the whole model region. Including the roughness of sea-ice into the calculation provides a more realistic forcing function of the ice dynamics.

After outlining the sea-ice model in Section 2 and introducing the model variable sea-ice roughness $R$ in Section 3 the aim of this article is to provide a transformation algorithm into statistics of small-scale roughness (Section 4) and its validation by comparisons with observations (Section 5). The results are discussed in Section 6, and Section 7 presents a first attempt to calculate roughness-dependent drag coefficients.

\section{The model}

Our dynamic-thermodynamic sea-ice model (Hibler, 1979; Harder et al., 1998) considers seaice as a 2-dimensional continuum which is described by the variables ice concentration $A$, drift velocity $\boldsymbol{u}$, ice thickness (volume per area) $h$ and ice roughness $R$. The ice rheology is based on the viscous-plastic model of Hibler (1979), and the surface energy balance is formulated according to Parkinson and Washington (1979). Daily atmospheric forcing data for surface winds and air temperatures are taken from reanalyses of the National Centers for Environmental Prediction (NCEP)/National Center for Atmospheric Research (NCAR) Reanalysis Project for 1979-1997. Data for humidity are taken from European Centre for Midrange Weather Forecast (ECMWF) analyses due to insufficiencies in the NCEP/NCAR data (Harder et al., 1998). Cloudiness and precipitation rate are described as spatially constant climatological monthly means. Daily values are derived by linear interpolation. Spatially varying, temporally constant ocean currents and oceanic heat fluxes are taken from the coupled ice-ocean model of Hibler and Zhang (1994). The model runs on a rotated spherical grid covering the whole Arctic with a spatial resolution of $1^{\circ}(\approx 110 \mathrm{~km})$, and a daily time step is employed.

\section{Simulated large-scale sea-ice roughness}

Sea-ice roughness $R$ (= deformation energy) is introduced as a scalar variable, describing a property of the ice (Harder, 1997). It is derived from temporal integration of deformation work per area and time given in $\mathrm{J} \mathrm{m}^{-2}$. Its spatial and temporal evolution is described by the prognostic budget equation

$\frac{\partial R}{\partial t}+\nabla \cdot(\mathbf{u} R)=\sigma \dot{\varepsilon}+m_{\mathrm{R}} \frac{R}{h} \min \left(0,\left.\frac{\partial h}{\partial t}\right|_{\text {thermo }}\right)$

The left-hand side has the form of a continuity equation and describes the local rates of change and advection. On the right-hand side source and sink terms are described. Wind and ocean current act as sources of deformation work. They induce energy into the ice and produce internal stresses which are demolished by deformation. Associated 
with this, internal forces perform mechanical work and thereby increase ice roughness. The work performed by internal forces is derived as the product of the stress tensor $\sigma$ and the strain rate $\dot{\varepsilon}$ by standard continuum mechanics (Rothrock, 1975). New ice has no initial roughness. Melting, represented by the last term in eq. (1), acts as a sink of roughness. This term, formulated as

$\frac{1}{R} \frac{\partial R}{\partial t}=m_{\mathrm{R}} \frac{1}{h} \min \left(0,\left.\frac{\partial h}{\partial t}\right|_{\text {thermo }}\right)$,

describes the decrease of roughness proportional to the melting of ice thickness $h$. The proprtionality factor is set to $m_{\mathrm{R}}=1$ which means that the roughness $R$ vanishes at the same rate as the ice thickness decreases. Davis and Wadhams (1995) derive a decline in mean pressure ridge keel draft of $0.625 \mathrm{~m}$ per degree latitude from upward looking sonar (ULS) data in the Greenland Sea which suggests a faster melt rate for deformed ice compared to an overall reduction in mean ice draft of $0.34 \mathrm{~m}$ per degree (Wadhams, 1992). This would support a higher value of $m_{\mathrm{R}}>1$. On the other hand, model studies (Omstedt and Svensson, 1992) show a decreasing melt rate with increasing pressure ridge frequency, supporting a lower value of $m_{\mathrm{R}}<1$.

Fig. 1 shows the spatial distribution of the mean deformation energy in winter (January-March). Deformation energy is lowest in the net freezing regions on the Siberian shelf, increases towards the central Arctic and has its highest values in the Canadian Archipelago and north of Greenland. Typical values in the central Arctic are about $100 \mathrm{~kJ} \mathrm{~m}^{-2}$. The interannual variability of the simulated mean winterly deformation energy (Fig. 2) shows highest variances along the shelf in the East Siberian Sea, in a small region north-east of Greenland and in the Beaufort Sea demonstrating that highest interannual variability is not naturally correlated with highest deformation energies. As the ice drift is mainly wind driven these variations are mainly due to anomalies in the atmospheric pressure system (Hilmer et al., 1998). The areas of strongly deformed ice north and north-west of Greenland show relatively low interannual variations. This suggests that deformed ice which has been advected to a large fraction with the Beaufort Gyre and Transpolar Drift accumulates in this region where nearly

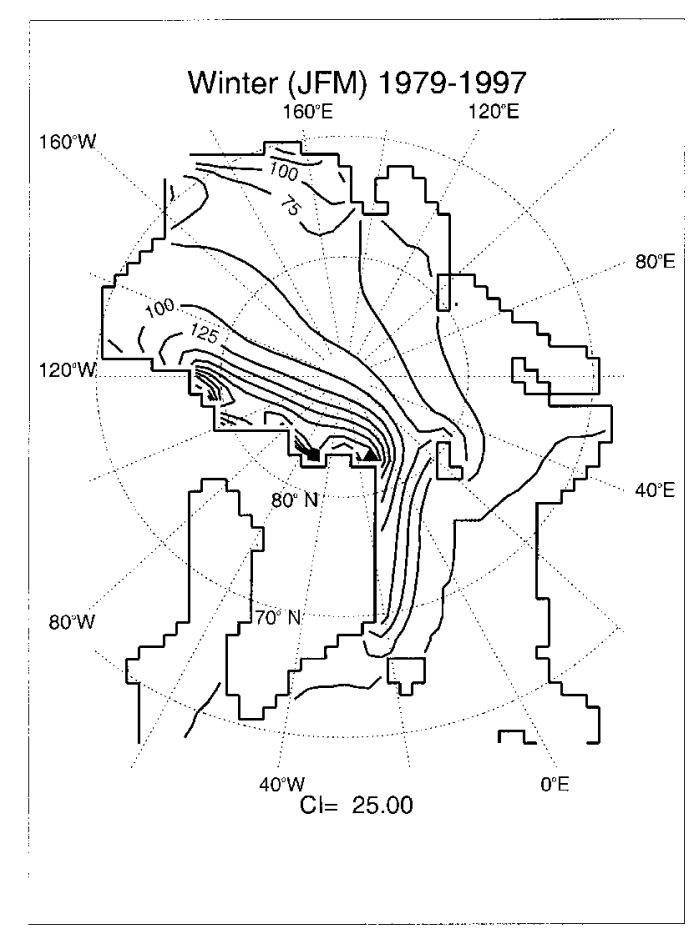

Fig. 1. Simulated deformation energy per area $R$ $\left(\mathrm{kJ} \mathrm{m}^{-2}\right)$ in winter (January-March), mean of 1979-1997.

every movement has died down. A substantial part of the ridge build-up, however, occurs in regions which are also highly variable, e.g., the East Siberian and Beaufort Sea and a restricted part north-east of Greenland where the open Fram Strait allows the ice to move again. The simulation also indicates that observations of pressure ridge distributions which are carried out in different years should be strongly correlated in the central Arctic and the mean part of the Canadian Archipelago as well as in the Laptev, Kara and Barents Seas whereas for example in the Beaufort Sea region interannual variations are quite common.

\section{Transformation to statistics of small-scale roughness features}

To use the large-scale sea-ice roughness for model validation, a parameterization scheme has been developed to transform simulated deforma- 


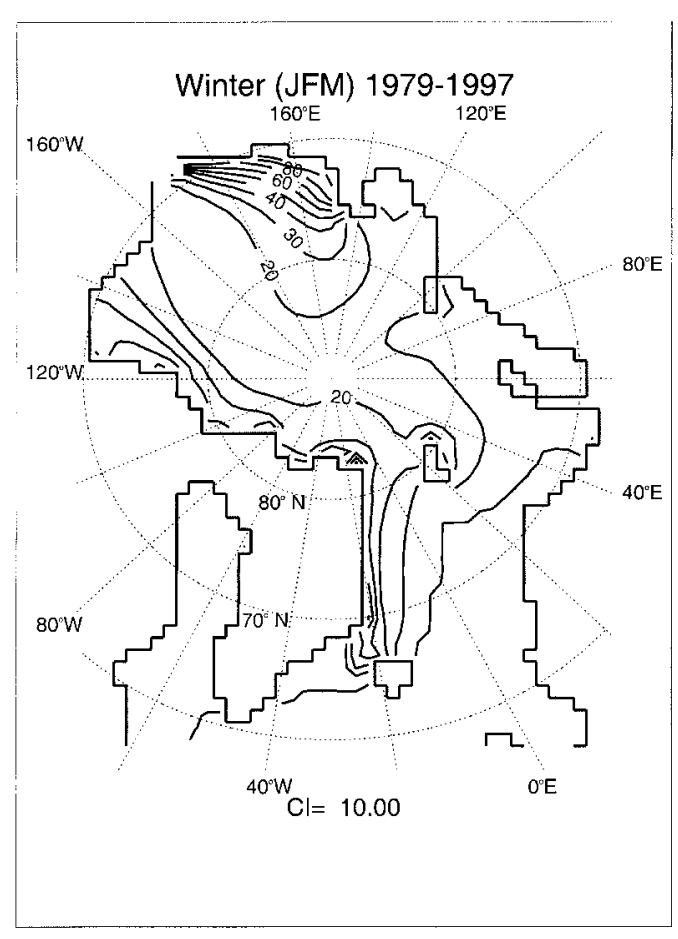

Fig. 2. Standard deviation of simulated deformation energy per area $R\left(\mathrm{~kJ} \mathrm{~m}^{-2}\right)$ in winter (January-March), mean of 1979-1997.

tion energy into observable features like pressure ridges. Number and height of pressure ridges are an observable measure for intensity and frequency of deformation processes in a region. A fraction of the total deformation energy described by the model variable $R$ is accumulated in pressure ridges as potential energy $P$ (Rothrock, 1975). We assume a linear relation

$$
P=c_{\mathrm{R}} \cdot R,
$$

with $c_{\mathrm{R}}=7.5 \%$ being the proportionality factor. Small-scale numerical simulations of ridge growth yield values of $c_{\mathrm{R}} \approx(5-20) \%$ (Hopkins et al., 1991; Hopkins and Hibler, 1991) and $c_{\mathrm{R}} \approx(5.9-10.4) \%$ (Hopkins, 1994). The simulated total potential energy per grid cell is considered the potential energy accumulated in all pressure ridges in a grid cell. The calculation of total accumulated potential energy makes use of knowledge about pressure ridge forms and distributions obtained from field observations. Pressure ridges are an agglomeration of ice fragments arranged along a fracture zone. Observations show no standardized form or size (Weeks et al., 1971; Timco and Burden, 1997; Wadhams, 1998). However, it may be stated that consistently for all pressure ridges longitudinal extension exceeds lateral dimension up to several orders of magnitude. In lateral direction pressure ridges have a wide base which narrows towards the top. This is also suitable for the ice subsurface whereby the extension of a ridge keel is clearly larger than of a sail. A triangle with rounded crest seems to be the most realistic description of a pressure ridge profile (Wadhams, 1998). To achieve a quite universal description of ridge profiles, which is a good approximation to the statistical mean of observed pressure ridge forms (Davis and Wadhams, 1995; Melling and Riedel, 1995; Timco and Burden, 1997; Wadhams, 1998), we assume an idealized ridge geometry with Gaussian-shaped keel and sail profiles (Fig. 3). At the points of inflection the bell-shaped curve is continued with the inflectional tangents. The formation of pressure ridges from ice fragments also supports the chosen geometry (Parmerter and Coon, 1972). Ridge width and volume, respectively, is calculated dependent of ridge height and prescribed angle of gradient. Sail slope $\alpha_{\mathrm{s}}=23^{\circ}$ and keel slope $\alpha_{\mathrm{k}}=$ $30^{\circ}$ (from Davis and Wadhams (1995)) are in good agreement with observed mean angles of gradient which are mainly between $20^{\circ}$ and $25^{\circ}$ for sails and between $20^{\circ}$ and $35^{\circ}$ for keels (Kovacs, 1971; Davis and Wadhams, 1995; Wadhams, 1998) and model studies (Parmeter and Coon, 1972).

The idealization smooths the natural roughness retaining the large features but loosing detail.

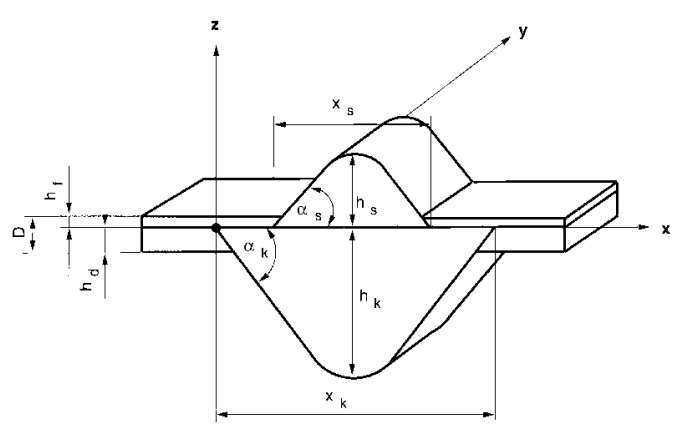

Fig. 3. Idealized ridge geometry with Gaussian-shaped keel and sail profiles. Variables are sail height $h_{\mathrm{s}}$, keel draft $h_{\mathrm{k}}$, ice thickness $D=h / A$, freeboard of level ice $h_{\mathrm{f}}$, draft of level ice $h_{\mathrm{d}}$, sail width $x_{\mathrm{s}}$, keel width $x_{\mathrm{k}}$, sail slope $\alpha_{\mathrm{s}}$ and keel slope $\alpha_{\mathrm{k}}$. 
Rothrock and Thorndike (1980) show that this kind of smoothing has little effect on the distribution of draft. The combination of surface topography measurements with ice draft measurments (Wadhams, 1980; Haas et al., 1997, 1998a) shows that ice roughness elements, observed on the ice surface, can be found on the ice subsurface as well. In the other horizontal dimension $(y)$ pressure ridges continue linearly. The potential energy of a pressure ridge $P=\rho V g h_{\mathrm{g}}$ (Rothrock, 1975), with density $\rho$, volume $V$, gravitational acceleration $g$ and the height of the center of gravity $h_{\mathrm{g}}$, is therefore calculated for the total ridge width $\left(x_{k}\right)$ and $1 \mathrm{~m}$ length $(y)$. The potential energy of a ridge $P_{k}$ in $\mathrm{J} \mathrm{m}^{-1}$, is calculated as a function of keel draft $h_{\mathrm{k}}$ :

$P_{k}\left(h_{k}\right)=\Delta \rho g\left(c_{1} h_{\mathrm{k}}^{3}-c_{2} D h_{\mathrm{k}}^{2}\right)$.

$\Delta \rho=\rho_{\mathrm{w}}-\rho_{\mathrm{i}}$ is the difference between the density of water $\rho_{\mathrm{w}}\left(=1025 \mathrm{~kg} \mathrm{~m}^{-3}\right)$ and ice $\rho_{\mathrm{i}}(=910$ $\left.\mathrm{kg} \mathrm{m}^{-3}\right), D=h_{\mathrm{d}}+\mathrm{h}_{\mathrm{f}}$ (Fig. 3) is the mean level ice thickness, and $c_{1}=0.318, \quad c_{2}=0.373$ are dimensionless constants derived from the volume calculation based on the Gaussian shape. Observations show that keel and sail height distributions fit a negative exponential (Davis and Wadhams, 1995). Therefore, an exponential distribution form for the number of keels $/ \mathrm{km}$ track $/ \mathrm{m}$ of draft increment

$N\left(h_{\mathrm{k}}\right)=n_{\mathrm{R}} \frac{1}{h_{\mathrm{m}}-h_{0}} \exp \left(\frac{h_{0}-h_{\mathrm{k}}}{h_{\mathrm{m}}-h_{0}}\right)$

is applied, with mean keel draft $h_{\mathrm{m}}$ and low-level cut-off draft $h_{0}$. For the calculation cut-off draft is prescribed with $h_{0}=h_{\mathrm{d}}+75 \mathrm{~cm}, h_{\mathrm{d}}$ being the mean floe draft. For comparisons with observations only ridges are counted which are deeper than the cut-off draft used in observations, usually $5 \mathrm{~m}$ or $9 \mathrm{~m}$. For sail frequencies, respectively, only sails higher than the cut-off value for sails, usually between $70 \mathrm{~cm}$ and $90 \mathrm{~cm}$, are counted. To close the system of equations, an empirical assumption (closure hypothesis) is required to relate the ridge frequency $n_{\mathrm{R}}$ (number of keels $/ \mathrm{km}$ of cruise track) to the large-scale deformation energy $R$. Our closure hypothesis is based on the following assumptions that are in physically reasonable agreement with available observations: first, the ridge frequency $n_{\mathrm{R}}$ should of course be zero when there is no deformed ice, i.e., when the large-scale deformation energy per area $R$ is zero. Second, the ridge frequency increases when the large-scale deformation energy increases. That is, the areal density of pressure ridges is correlated with the total energy stored in them. Third, this relation is nonlinear, with the ridge frequency $n_{\mathrm{R}}$ increasing less rapidly than the total deformation energy $R$ because of two associated processes: for a given increase in deformation energy, both the mean size of the ridges and their frequency in space are increased. Both processes are competingly fed by the total increase in deformation energy. The energy stored in ridges is proportional to their areal frequency (given a fixed ridge size distribution) but depends nonlinearily on the ridge size (eq. (4)). This dependence causes the ridge frequency to increase rapidly with increasing deformation energy as long as the ridges are small, but slower when the ridges get larger and the potential energy stored in them grows rapidly. Details of ridging processes are discussed and investigated by small-scale ridging studies (Parmerter and Coon, 1972; Rothrock, 1975; Hopkins et al., 1991; Hopkins and Hibler, 1991; Hopkins, 1994) that provide the physical base for our study.

For the model simulation, we assume a relationship between ridge frequency $n_{\mathrm{R}}$ and large-scale deformation energy $R$

$n_{\mathrm{R}}=\frac{1}{c_{\mathrm{n}}}\left(\frac{R}{h}\right)^{q}$

with $q$ being an exponent in the range $0<q<1$. For the standard simulation, $q=1 / 2$ (square-root relation) is used. A sensitivity study with $q=2 / 3$ shows similar results, indicating that the absolute value of $q$ is not very critical to the simulation. An optimization of this parameter will be done when more extensive field observations provide a more sound relationship between large-scale deformation energy and ridge frequency (or areal density) than the presently available observations.

The proportionality constant $c_{\mathrm{n}}$ in eq. (6) is also an empirical constant. As the sparse observational data give no direct measurements for $c_{\mathrm{n}}$, its value is determined by an inverse method which requires that the derived spatial ridge-frequencies match the observations. (This method is a standard technique in climate modelling, similar to adjusting eddy viscosities in ocean or atmosphere models.) We use $c_{\mathrm{n}}=14 \cdot 10^{3} \mathrm{~J}^{1 / 2} \mathrm{~m}^{-1 / 2}$ according to com- 
parisons with observed pressure ridge spatial frequencies on the surface from Wittmann and Schule (1966) in Weeks et al. (1971) and on the subsurface from Bourke and McLaren (1992). Other measurements (Davis and Wadhams, 1995; Haas et al., 1998a; Melling and Riedel, 1995; Wadhams, 1992) are taken as independent data sets to validate the model.

Solving the integral of the potential energy equation

$P=\int_{h_{0}}^{+\infty} P_{k}\left(h_{k}\right) N\left(h_{\mathrm{k}}\right) \mathrm{d} h_{\mathrm{k}}$,

with the simulated potential energy $P$, given in $\mathrm{J} \mathrm{m}^{-2}$ (eq. (3)), on the left-hand side, $P_{k}\left(h_{k}\right)$ in $\mathrm{J} \mathrm{m}^{-1}$ from eq. (4) and $N\left(h_{\mathrm{k}}\right)$ in $\mathrm{m}^{-2}$ from eq. (5) on the right-hand side, leads to a cubic equation for the mean keel draft $h_{\mathrm{m}}$ which has one real solution. Ridge spatial frequency can be calculated from the mean keel draft $h_{\mathrm{m}}$ as well as mean sail height when using a constant keel to sail ratio $r$. According to observations (Tucker, 1989) $r$ is set to 4.5. To calculate volumetric and areal fraction of deformed ice we assume that pressure ridges are composed of deformed ice including 20\% amount of air enclosure (Melling and Riedel, 1995). Additionally a fraction of the apparently level ice around a pressure ridge shall be regarded as deformed as well, here twice the width of a pressure ridge. Eicken et al. (1995) obtain from field measurements that about $27 \%$ of the apparently level ice are deformed.

\section{The model validation}

An extensive validation regarding the model dynamics has been performed during the Sea Ice Model Intercomparison Project (SIMIP) (Harder, 1997; Kreyscher et al., 1997; Lemke et al., 1997). Therefore we will focus on the validation of the parameterization scheme described above. The charts of submarine-borne sonar data by Bourke and McLaren (1992) have been used to tune the model parameter $c_{\mathrm{n}}$. The illustrated spatial distributions of keel drafts are in close agreement with the model results (Steiner et al., 1998a). Observations from submarine-borne sonar taken up in May 1987 (Wadhams, 1992) show typical concentrations and mean keel drafts for keels deeper than $5 \mathrm{~m}$ of $4-20$ ridges $\mathrm{km}^{-1}$ and $8-10.5 \mathrm{~m}$ in the Arctic Basin, 3-7 $\mathrm{km}^{-1}$ and $7.5-8.2 \mathrm{~m}$ in the approaches to Fram Strait, $0-7 \mathrm{~km}^{-1}$ and $6-7.5 \mathrm{~m}$ in the northern Greenland Sea $\left(78^{\circ}-80^{\circ} \mathrm{N}\right)$, and $0-2 \mathrm{~km}^{-1}$ and $5-7 \mathrm{~m}$ in the Greenland Sea south of $78^{\circ} \mathrm{N}$. North of Greenland meen pressure ridge keel draft increases to values of $12-13 \mathrm{~m}$ (Davis and Wadhams, 1995). The simulated mean keel draft (Fig. 4) shows quite similar values with about $11 \mathrm{~m}$ in the central Arctic and decreasing continually along the $0^{\circ}$-meridian through the Fram Strait to values of $5-7 \mathrm{~m}$ south of $78^{\circ} \mathrm{N}$. Simulated ridge concentrations (Fig. 5) are decreasing in a similar manner from about $11 \mathrm{~km}^{-1}$ in the central Arctic to $0-7 \mathrm{~km}^{-1}$ south of $78^{\circ} \mathrm{N}$. Highest simulated values up to $14 \mathrm{~m}$ keel draft and 13-14 ridges $\mathrm{km}^{-1}$ are derived north of Greenland and in the coastal regions of the Canadian Archipelago, which is in close agreement to the observations. Good correlation is as well given for the submarine sonar data collected during the U.S. Navy cruise L2-92 in April 92 (NSIDC, 1998) along about $150^{\circ} \mathrm{W}$. Mean values between 80 and $88^{\circ} \mathrm{N}$ are $9.4 \mathrm{~m}$ compared to

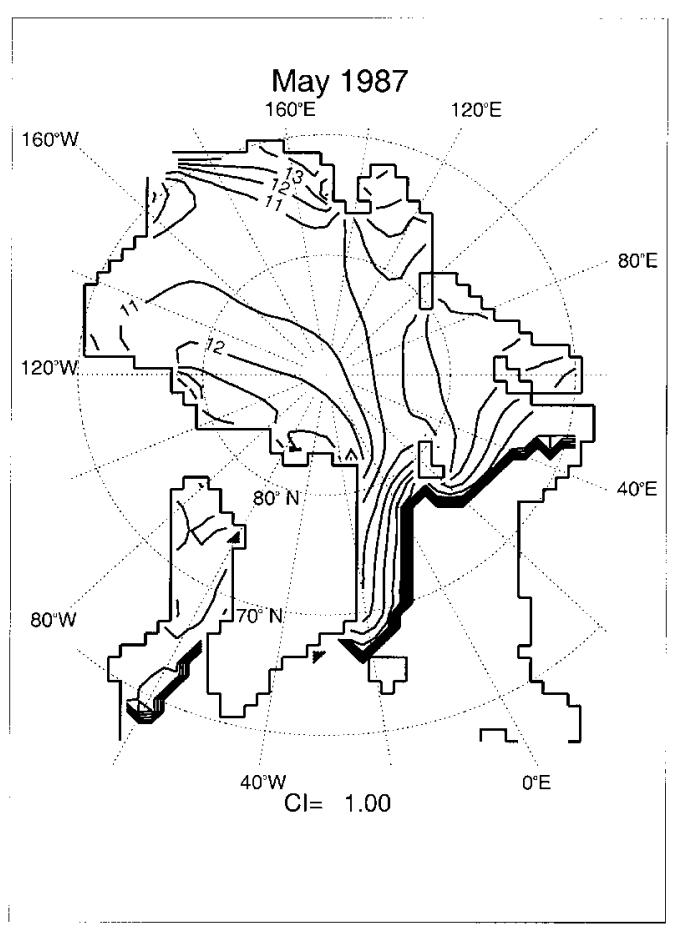

Fig. 4. Simulated mean pressure ridge keel draft (m) for May 1987. 


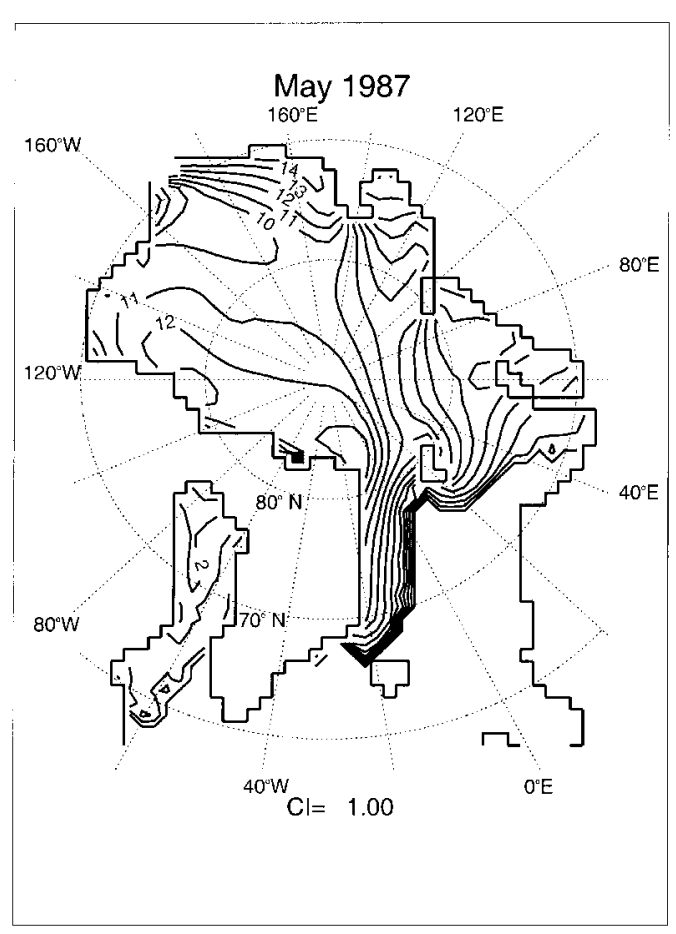

Fig. 5. Simulated mean pressure ridge spatial frequency (number of ridges exeeding $5 \mathrm{~m} \mathrm{keel} \mathrm{draft} / \mathrm{km}$ ) for May 1987.

$10-11 \mathrm{~m}$ in the simulation and 8 ridges $\mathrm{km}^{-1}$ compared to $7-9 \mathrm{~km}^{-1}$ in the model, with a slightly decreasing tendency towards the North pole. Compared to the mean values of May 1979-1997 (e.g., Fig. 6), 1987 represents abnormal high values in the East Siberian Sea with 11-14 m and $12-15 \mathrm{~km}^{-1}$ in contrast to $10-12 \mathrm{~m}$ and $10-13 \mathrm{~km}^{-1}$ in the mean and a lower gradient towards the Canadian Archipelago. Observed mean keel drafts in April reported by Romanov (1995, chart 32.44) show an increase from about $11 \mathrm{~m}$ in the central Arctic to about $15 \mathrm{~m}$ in the coastal regions of the Canadian Archipelago, and across the Beaufort Sea from about $8 \mathrm{~m}$ near Bering Strait up to $12 \mathrm{~m}$ in front of M'Clure Strait. In the Kara and Laptev Seas keel drafts are between $6 \mathrm{~m}$ and $8 \mathrm{~m}$ decreasing to about $5 \mathrm{~m}$ and lower beneath the Siberian coast. These values are in good correlation with our model results (Fig. 6). The simulated values in the East Siberian Sea seem to be somewhat overestimated although the observations, compared to the Laptev and Kara

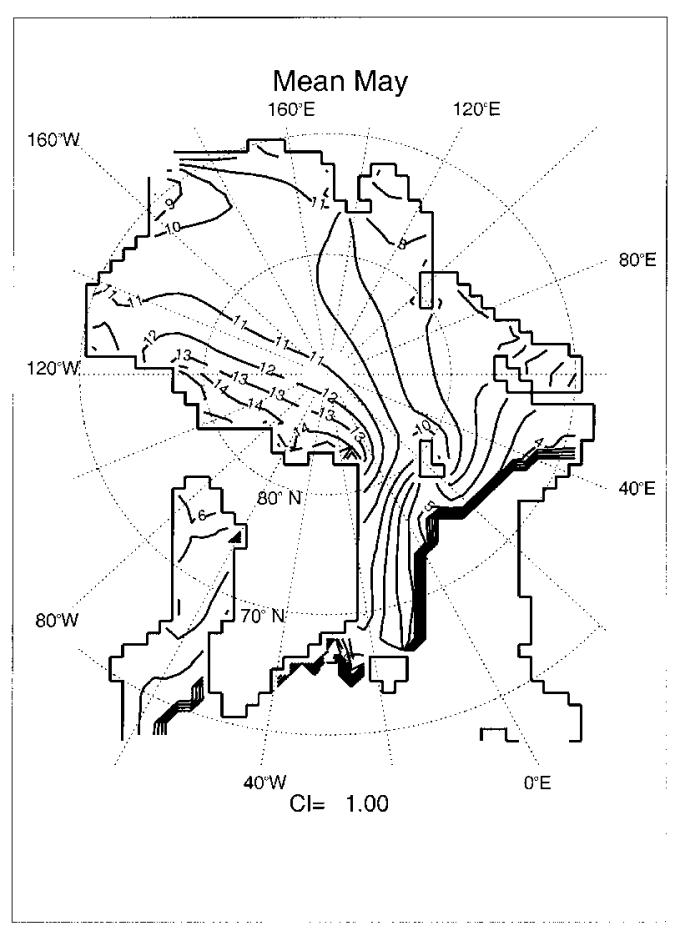

Fig. 6. Simulated mean pressure ridge keel draft (m) for May, mean of 1979-1997.

Sea drafts, show as well higher values in the East Siberian and Chuckchi Seas. The average sail height derived from airborne and direct measurements (Romanov, 1995) in the Chukchi Sea and the northern parts of the Barents, Kara, and Laptev Seas is $1.5-2.0 \mathrm{~m}$, while in the southern parts of these seas it is $1.0-1.5 \mathrm{~m}$ which compares well with our model results. Observed mean sail heights in the East Siberian Sea seem to be quite similar and therefore overestimated by the model. For the East Siberian Sea higher values compared to the Laptev and Kara Sea values are only evident in charts of maximum sail height (e.g., chart 32.36 in Romanov (1995)). For the Canadian region and north of Greenland, Romanov (1995) reports values varying from 2.5 to $3.15 \mathrm{~m}$ increasing toward the shores which is in close agreement with the simulation.

Melling and Riedel (1995) derive mean keel drafts of 8-9 $\mathrm{m}$ in the Beaufort Sea from moored ULS for April-May 1990 agreeing with submarine-borne sonar measurements in the same region and season of McLaren et al. (1984) and Wadhams 
and Horne (1980). The model simulations show somewhat higher values with $9-12 \mathrm{~m}$ in this region. Simulated values of ridge frequency are $8-13 \mathrm{~km}^{-1}$ in the Beaufort Sea for April-May 1990 and $10-12 \mathrm{~km}^{-1}$ in May 1987 (Fig. 5). In comparison, the observed ridge concentrations show large variations with 4-6 $\mathrm{km}^{-1}$ in Melling and Riedel (1995) and $8-15 \mathrm{~km}^{-1}$ in Wadhams and Horne (1980), whereas the different observations of mean keel drafts are in close agreement. This is not surprising, because divergence and convergence in the ice field lower or raise the frequency of keels without changing the geometry of the deep topographic features within it (Melling and Riedel, 1995). High interannual variances in this region are also indicated by Fig. 2. In Figs. 7, 8 simulated mean pressure ridge sail height and pressure ridge spatial frequency is shown for August 1996. In situ measurements in the Laptev Sea during this time (Haas and Lensu, 1997; Haas et al., 1998a) show mean sail heights between $1.0 \mathrm{~m}$ and $2.0 \mathrm{~m}$ and ridge sail frequencies of $5-10 \mathrm{~km}^{-1}$ which are in close agreement with simulated values of

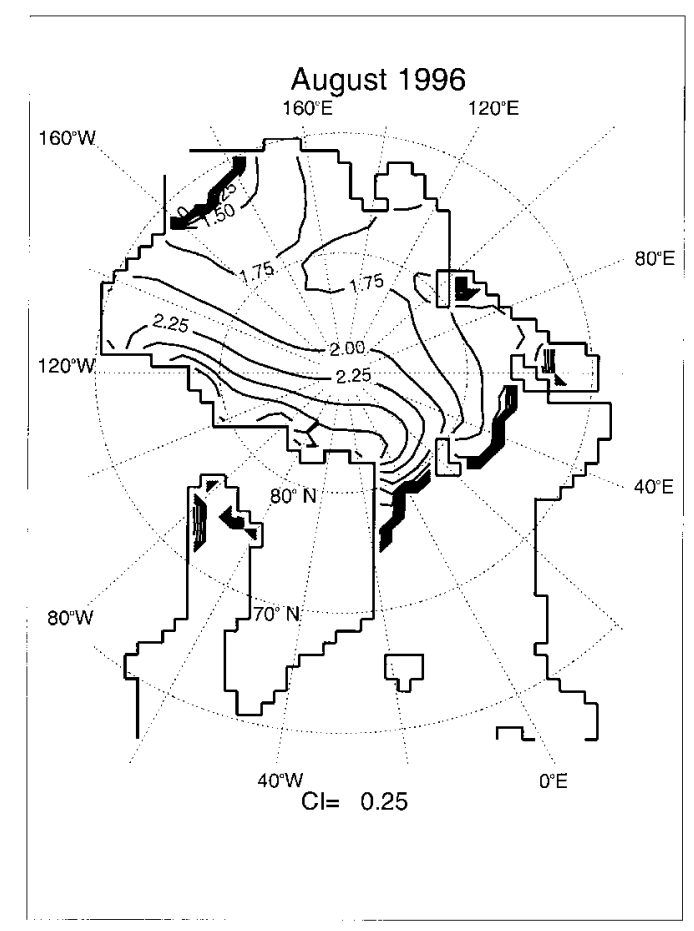

Fig. 7. Simulated mean pressure ridge sail height $(\mathrm{m})$ for August 1996.

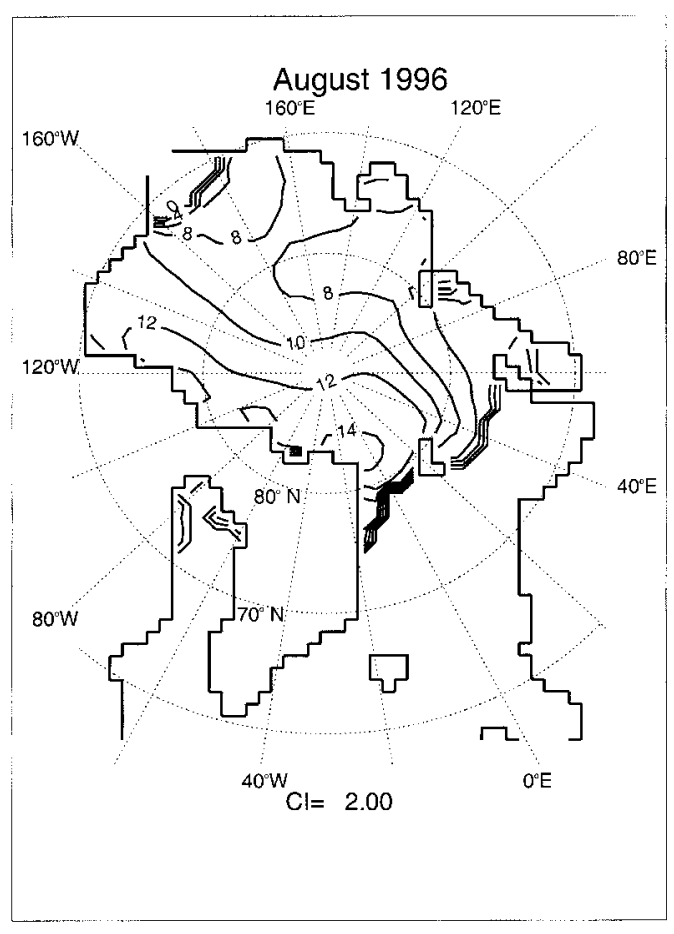

Fig. 8. Simulated mean pressure ridge spatial frequency (number of ridges exeeding $80 \mathrm{~cm}$ sail height $/ \mathrm{km}$ ) for August 1996.

$1.5-1.75 \mathrm{~m}$ and $6-8 \mathrm{~km}^{-1}$. In consistence with the model no clear dependence on geographical area was discerned within the Laptev Sea. Although the observed (Haas et al., 1998a) mean ice thickness and concentration in the Laptev Sea in 3 consecutive summers $(1995,1996,1997)$ show a large variability due to different atmospheric conditions whereas the interannual variations of ridge frequency were very low. This is represented in the simulation by very low variances of mean deformation energy in this region. Simulated volume fraction of deformed ice (Fig. 9) shows about $50 \%$ of deformed ice in the central Arctic.

\section{Discussion}

In a qualitative sense our calculations show a good correlation between model results and available field observations. The question may rise how this model can be validated when its parameters are apparently tuned to match the observations 


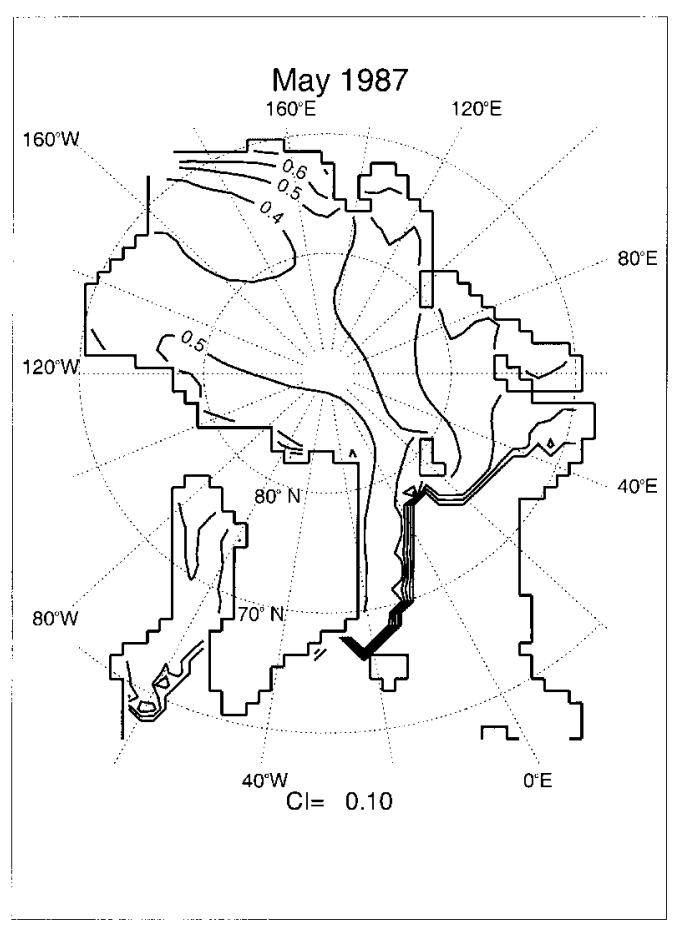

Fig. 9. Simulated mean deformed ice volume fraction for May 1987.

which could be the ground truth for model validation? Fortunately, this is a rhetoric question that can easily be answered by a couple of plausibility tests. First, eq. (6) for the ridge frequency is a spatially uniform function that is applied to all grid cells. Whereas the empirical parameter $q$ is fixed to a quite small range due to the known statistical properties of sea-ice ridges, the empirical parameter $c_{\mathrm{n}}$ can be used to tune the mean ridge frequency, but has no impact on the spatial distribution. Mean keel draft is hardly sensitive to variations in $c_{\mathrm{n}}$. All observations show a strong spatial variation of ridge height and frequency (Bourke and McLaren, 1992; Davis and Wadhams, 1995; Wadhams, 1992), providing an independent quantity to test the model. None of the model parameters can alter the general spatial pattern of ice roughness, thus the agreement of simulated spatial roughness patterns with observations is a verification of the model.

Second, the temporal changes in sea-ice roughness are another independent quantity. The relationship in eq. (6) is not time-dependent.
Therefore, the temporal evolution of ice roughness (e.g., as a mean over large areas, or as the temporal evolution of spatial anomalies) can be used for an independent model verification. While currently the temporal evolution of the ice roughness patterns is less well known than the mean spatial pattern, new remote sensing observations (Haas et al., 1998b; Liu et al., 1998) are expected to reduce this deficit drastically. Third, the number of observable quantities of sea-ice roughness (mean keel draft, mean sail height, keel and sail frequency, areal and volumetric fraction of deformed ice as well as the spatial and temporal evolution of the respective variables) exceeds the number of empirical model parameters. The number of independent verification quantities is larger than the number of tunable model parameters, indicating an overdetermined system of equations. A simultaneous agreement of all observable ice properties derived from the model with observations cannot be achieved by simply tuning model parameters but requires that the physical model itself represents realistic relations between the physical variables.

Such parameters as the ratio $r$ and keel and sail slopes as well as the parameter $q$ are, according to the observations, limited to a small range. When varied in this range they do not lead to substantial changes in the model results. $c_{\mathrm{R}}$ in eq. (3) may be another variable to tune the model, however it is derived from the results of smallscale ridging studies (Hopkins et al., 1991; Hopkins and Hibler, 1991; Hopkins, 1994). Changes within this range $\left(c_{\mathrm{R}}=5-10 \%\right)$ lead to maximum changes of about $1 \mathrm{~m}$ in keel draft, 0.5 in ridge frequency and $15 \%$ in volumetric fraction of deformed ice. These spatially and temporally constant changes of $c_{\mathrm{R}}$ neither affect spatial distribution nor temporal evolution.

Besides using the simulation results to validate the model the additional parameters can be used for statistical analyses to learn more about the variability of ice dynamics and deformation on different time scales. Some results are already discussed in Sections 3 and 5.

\section{Roughness-dependent drag coefficients}

The strength of air/ice/ocean exchange of momentum is described by the atmospheric and oceanic drag coefficients which are dependent both 
on roughness and stratification (Overland and Davidson, 1992; Overland and Colony, 1994). In the simulation we are using wind velocity in $2 \mathrm{~m}$ height. Therefore we assume that the appropriate stability parameterization is included in the analyses model and focus on the dependency on roughness. The introduction of the roughness variable into sea-ice models enables the application of roughness-dependent drag coefficients. Overland and Colony (1994) describe the surface layer $10-\mathrm{m}$ drag coefficient as a regional value of air-ice coupling which includes the influence of ridges and leads. Calculating drag coefficients as a function of sea-ice roughness accounts for the regional variations also lateral forces of floe edge form drag as described by Steele et al. (1989) cannot be explicitly considered. (The model is based on the continuity hypothesis considering sea-ice a 2-dimensional continuum where single floes and leads are not resolved.) Winds as the primary driving force (Thorndike and Colony, 1982; Hilmer et al., 1998) and ocean currents determine direction and strength of the ice motion in the Arctic. Therefore changes of drag coefficients at the ice-ocean and ice-atmosphere interfaces have an important effect on the resulting ice drift pattern. The respective model results can be validated quite well by comparing with observed drift buoys or Special Sensor Microwave/Imagerderived ice-drift data (Martin, 1998, personal communication). This has been effectively carried out during SIMIP (Harder, 1997; Kreyscher et al., 1997; Lemke et al., 1997). Temporally and spatially constant drag coefficients which are used in present-day sea-ice models cannot account for the enhanced frictional drag of strongly deformed ice. Model parameterizations (Raupach et al., 1993; Andreas, 1995; Steele et al., 1989) of form drag are very rare. Especially no attempt has been made to introduce contributions of form drag into climate models. Here the contribution of roughness elements to oceanic $\left(c_{\mathrm{w}}\right)$ and atmospheric $\left(c_{\mathrm{a}}\right)$ drag coefficients is included by calculating drag coefficients as linear functions of simulated sea-ice roughness $R$ (Fig. 10):

$c_{\mathrm{a}}=m_{\mathrm{a}} R+b_{\mathrm{a}}$,

$c_{\mathrm{w}}=m_{\mathrm{w}} R+b_{\mathrm{w}}$,

leading to drag coefficients which are variable in space and time. Similarly Banke et al. (1980) related the atmospheric drag coefficient linearly to a measurable surface parameter. Eqs. (8) and (9) are based on the drag partition theory proposed by Arya (1975) who divides the total drag into contributions of form drag and skin friction. The constants $\left(b_{\mathrm{w}}\right)$ and $\left(b_{\mathrm{a}}\right)$ represent the skin drag contribution which are set to the lowest observed values taken from a collection of observed drag coefficients listed in Omstedt (1998) and Squire (1998). The form drag contribution represented by the first terms on the right-hand side of eqs. (8) and (9) is zero for $R=$ 0 (no ice roughness) and reaches a maximum value for a maximum mean value of the simulated ice roughness of $R=350 \mathrm{~kJ} \mathrm{~m}^{-2}$. In this simulation we use $b_{\mathrm{w}}=2.4 \cdot 10^{-3}$ and $b_{\mathrm{a}}=$ $1.2 \cdot 10^{-3} ; \quad m_{\mathrm{w}}$ and $m_{\mathrm{a}}$ are calculated to $6.46 \cdot 10^{-8} \mathrm{~m}^{2} / \mathrm{J}$ and $1.94 \cdot 10^{-8} \mathrm{~m}^{2} / \mathrm{J}$, respectively, using maximum mean drag coefficients of $c_{\mathrm{w}}=25.0 \cdot 10^{-3}$ and $c_{\mathrm{a}}=8.0 \cdot 10^{-3}$. The parameters are optimized by comparing the observed mean daily ice drift velocity with the corresponding model velocity where the buoy drift data is derived from the International Arctic Buoy Programme (IABP) (Colony and Rigor, 1995). This method was already used during SIMIP to adjust the drag coefficient ratio $c_{\mathrm{a}} / c_{\mathrm{w}}$ for models with different rheology (Kreyscher et al., 1997; Kreyscher, 1998). The applied parameterization leads to a spatial distribution of drag coefficents (Abb. 11, 12) with low values of about $c_{\mathrm{w}}=$ $(2-4) \cdot 10^{-3}$ and $c_{\mathrm{a}}=(1.2-1.6) \cdot 10^{-3}$ in the Siberian part of the Arctic Ocean increasing to $c_{\mathrm{w}}=8.0 \cdot 10^{-3}$ and $c_{\mathrm{a}}=2.8 \cdot 10^{-3}$ in the central Arctic and reaching highest values of about $c_{\mathrm{w}}=$ $(18-20) \cdot 10^{-3}$ and $c_{\mathrm{a}}=(6.4-7.6) \cdot 10^{-3}$ near to the north coast of Greenland and the Canadian Archipelago. Fig. 10 shows a much faster increase for the oceanic than for the atmospheric drag coefficient indicating increasing importance of the oceanic contribution for strongly deformed ice. This is also illustrated in Fig. 13 showing the winterly mean of the ratio of the atmospheric to the oceanic drag coefficient with decreasing values towards regions with stronger deformed ice. The constant value of 0.5 which is used in the control run, with respect to the SIMIP results, is only found near the ice edges whereas the ratio is decreasing to values of 0.35-0.4 in the central Arctic up to 0.3 in the highly deformed regions north of Greenland.

Tellus 51A (1999), 5 


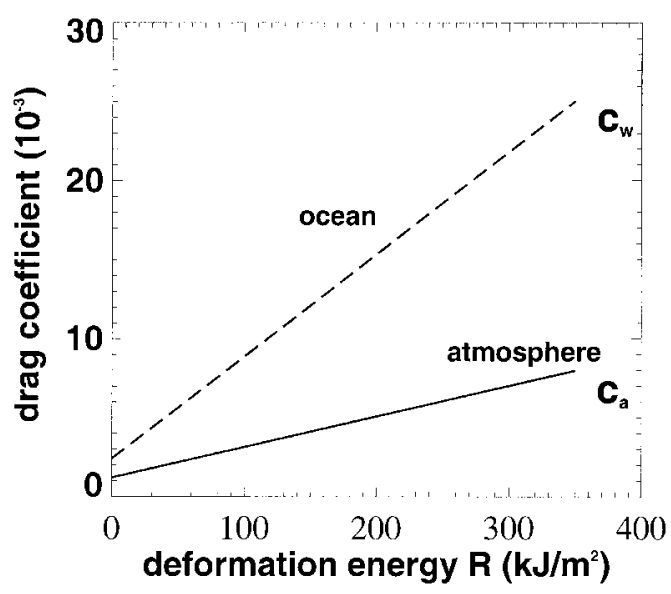

Fig. 10. Oceanic $\left(c_{\mathrm{w}}\right)$ and atmospheric $\left(c_{\mathrm{a}}\right)$ drag coefficients parameterized as linear functions of deformation energy $R$.

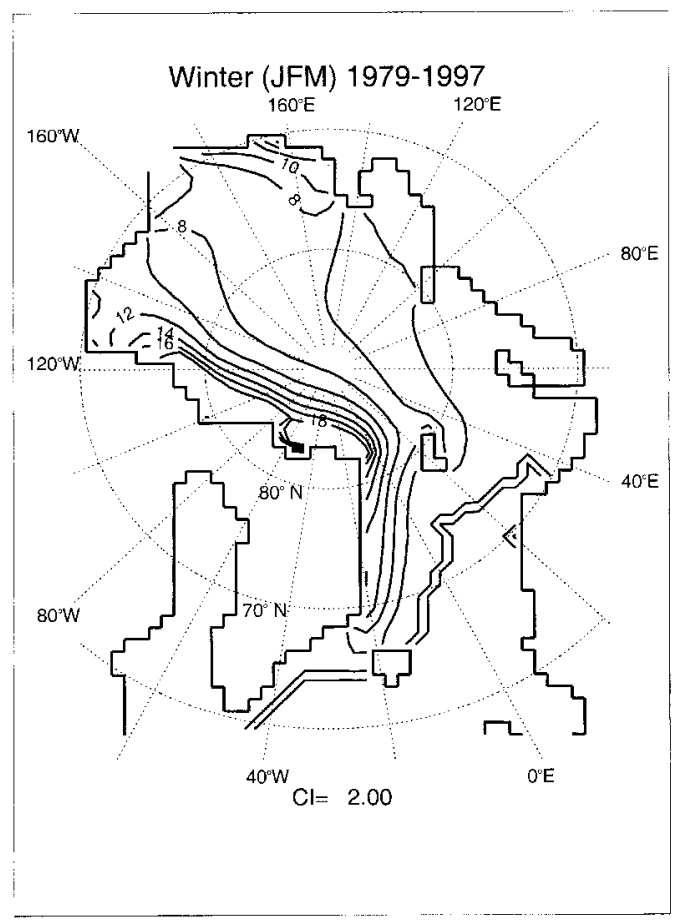

Fig. 11. Oceanic drag coefficient $\left(c_{\mathrm{w}}\right)$ in winter (JanuaryMarch) (1979-1997). Drag coefficients are calculated as a function of deformation energy (Fig. 10).

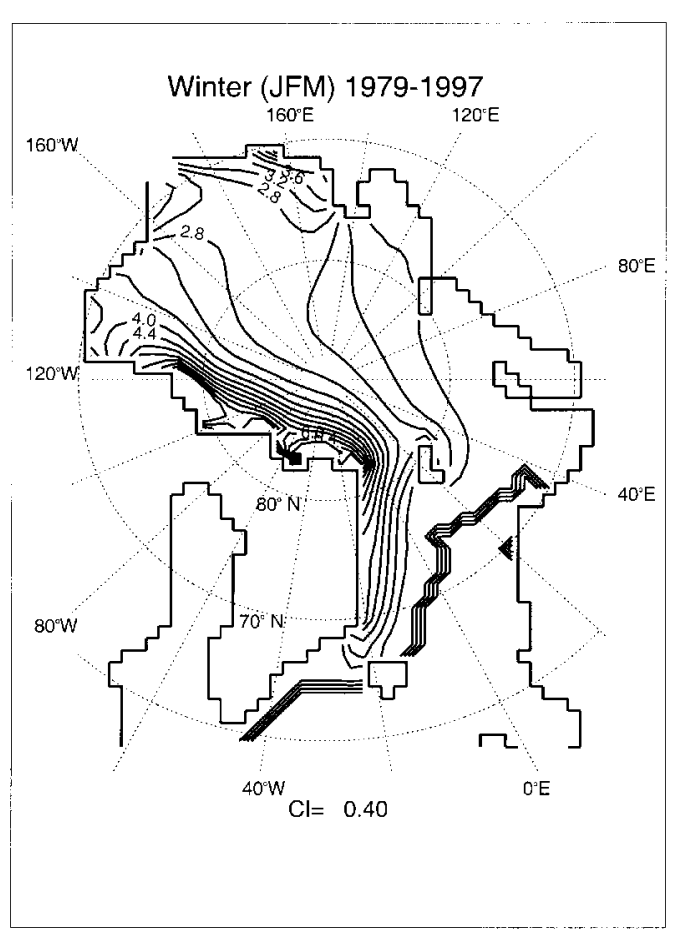

Fig. 12. Atmosheric drag coefficient $\left(c_{\mathrm{a}}\right)$ in winter (January-March) (1979-1997). Drag coefficients are calculated as a function of deformation energy (Fig. 10).

The resulting effect on the mean ice drift is shown in Fig. 14. Using roughness-dependent drag coefficients leads to a reduction of drift velocities in the Beaufort gyre and in the Kara and Laptev Sea outflow of up to $1 \mathrm{~cm} \mathrm{~s}^{-1}$ which is about a third of the maximum mean drift velocities in these outflow regions. The weakening of the East Greenland Current of up to $2 \mathrm{~cm} \mathrm{~s}^{-1}$ compared to $12 \mathrm{~cm} \mathrm{~s}^{-1}$ maximum mean velocities seems to be less important, but nevertheless influences the ice export through the Fram Strait and therefore the freshwater flow into the North Atlantic Ocean. Ice stoppage is decreased northeast of Greenland leading to higher and more realistic ice drift velocities in this region. Ongoing studies which are including ice concentration into the parameterization of form drag are leading to an enhanced seasonal variability, indicating that seasonal changes in the neutral-stability drag coefficients are mainly due to form drag of floe edges (Steiner, 1999). 


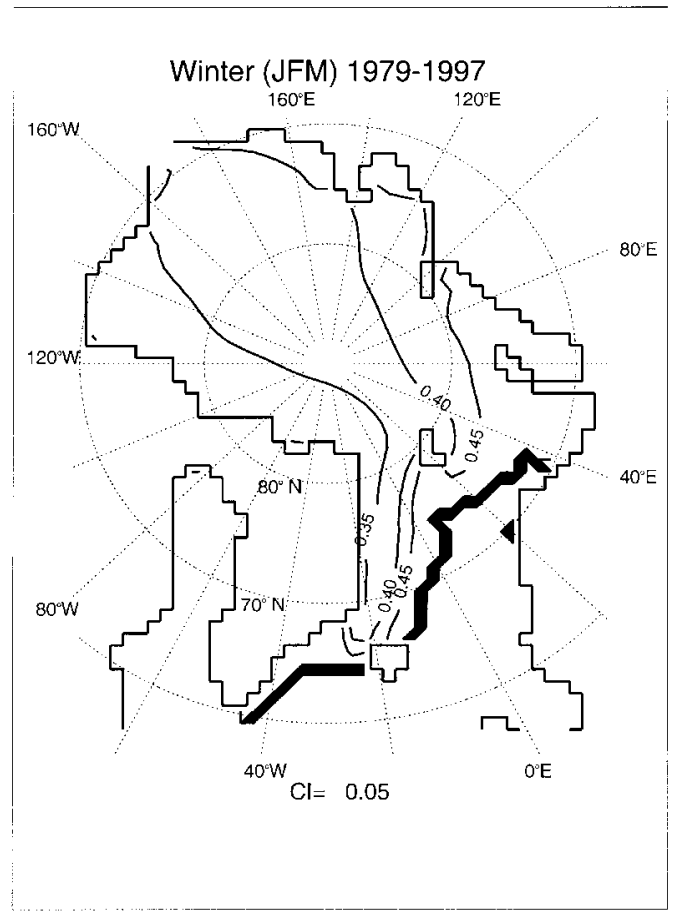

Fig. 13. Ratio of atmospheric $\left(c_{\mathrm{a}}\right)$ to oceanic $\left(c_{\mathrm{w}}\right)$ drag coefficient in winter (January-March) (1979-1997). Drag coefficients are calculated as a function of deformation energy (Fig. 10).

\section{Conclusions}

Besides dynamics and thermodynamics of seaice, roughness is an important parameter to characterize sea-ice. The aim of this work has been to introduce sea-ice roughness as an additional variable to validate model results. Based on the idea that pressure ridge distributions are a measure of accumulated deformation processes a parameterization scheme has been developed to transform simulated large-scale deformation energy into observable quantities like pressure ridge height and frequency and volumetric and areal fractions of deformed ice. An idealized ridge geometry with Gaussian-shaped keel and sail profiles is used as well as an exponential distribution of ridge drafts and heights. The potential energy accumulated in pressure ridges is given as a fraction of total simulated deformation energy. Total number of ridges is calculated as a function of deformation energy where the values of two empirical constants

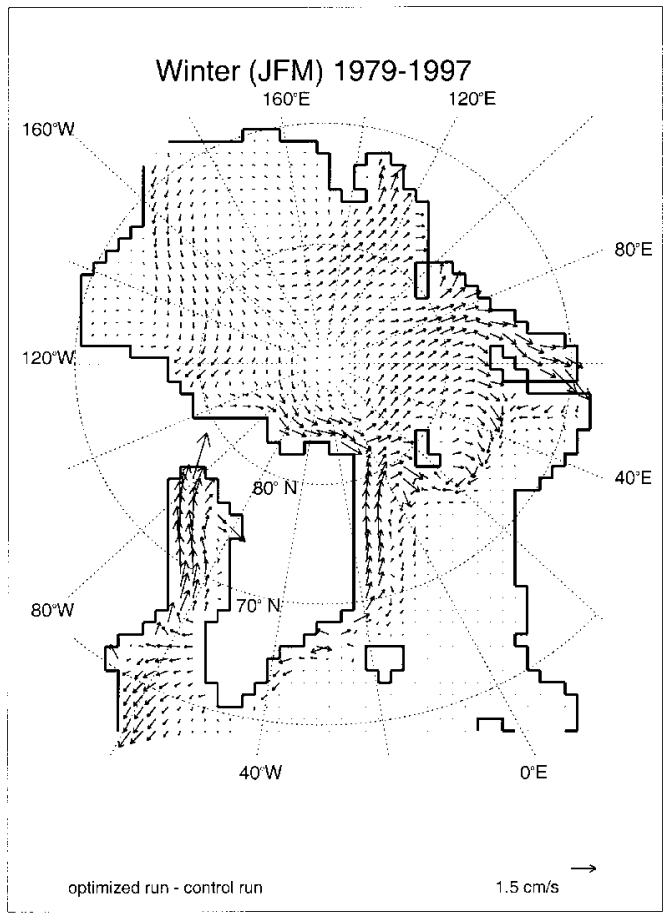

Fig. 14. Mean ice drift velocities difference. Model run with variable drag coefficients as shown in Fig. 10 minus control run with constant drag coefficients for winter (January-March) (1979-1997).

are determined by fitting to observations. Independent data sets are used to test the parameterization scheme. Spatial distributions from ULS and laser altimeter measurements are in close agreement with simulated pressure ridge distributions.

The introduction of roughness-dependent drag coefficients is an additional step towards an optimized description of sea-ice dynamics in the model and allows to efficiently consider the effect of form drag from roughness elements in coupled climate models. As a first attempt drag coefficients at the ice-ocean and ice-atmosphere interfaces are calculated as linear functions of sea-ice roughness. With this assumption drag coefficients can be described as temporally and spatially varying quantities, leading to a more realistic description of momentum exchange between atmosphere, ice and ocean. The resulting effect is an enhanced importance of the oceanic contribution in regions with strongly deformed ice connected with changes in 
the ice drift field. The results we achieved in this study are a fundamental supposition to make observed roughness statistics usable to verify model results. Especially high-resolution satellite data can be included in the model validation in the near future. Furthermore, long-term model simulations of roughness variables may be used to study seasonal, interannual and decadal variations of sea-ice dynamics and deformation processes. To optimize the empirical parameters and for further confirmation of the parameterization scheme more extensive field observations are necessary. Problems may arise due to insufficient forcing data (Harder et al., 1998) especially in the ice margin. Certainly one reason is the temporally constant oceanic forcing which causes deficiencies mainly in the Greenland and Norwegian Sea. Coupling to an ocean model which is one of the near future tasks will remove these deficiencies.
The roughness-dependent parameterization of thermodynamic and dynamic processes is an important assumption for further examinations of boundary layer processes on the surface and subsurface of sea-ice which are necessary for further model optimization.

\section{Acknowledgments}

The authors would like to thank C. Haas for providing laser altimeter data and T. Martin for constructive discussions. Funding by the German Federal Ministry of Education, Research and Technology under the project "Remote sensing of sea-ice properties and processes" (grant 03PL018A) is gratefully acknowledged. Atmospheric forcing data were derived from NCEP/NCAR reanalyses and ECMWF analyses.

\section{REFERENCES}

Andreas, E. L. 1995. Air-ice drag coefficients in the western Weddell Sea 2. A model based on form drag and drifting snow. J. Geophys. Res. 100(C3), 4833-4843.

Arya, S. P. S. 1975. A drag partition theory for determining the large-scale roughness parameter and wind stress on the Arctic pack ice. J. Geophys. Res. 80, 3347-3454.

Banke, E. G., Smith, S. D. and Anderson, R. 1980. Drag coefficients at AIDJEX from sonic anemometer measurements. In: Sea ice processes and models (ed. Prichard, R. S.). Univ. of Washington Press, Seattle, 430-442.

Bourke, R. H. and McLaren, A. S. 1992. Contour mapping of Arctic basin ice draft and roughness parameters. J. Geophys. Res. 97(C11), 17,715-17,728.

Carlström, A. and Ulander, L. M. H. 1995. Validation of backscatter models for level and deformed sea ice in ERS-1 SAR images. Int. J. Rem. Sens. 16, 3245-3266.

Colony, R. L. and Rigor, I. 1995. Arctic ocean buoy data program report. Appl. Phys. Lab. Techn. Mem. APL-UW TM 10-91.

Davis, N. R. and Wadhams, P. 1995. A statistical analysis of Arctic pressure ridge morphology. J. Geophys. Res. 100(C6), 10,915-10,925.

Dierking, W. 1995. Laser profiling of the ice surface topography during the Winter Weddell Gyre Study 1992. J. Geophys. Res. 95(C3), 4807-4820.

Dierking, W., Carlström, A. and Ulander, L. M. H. 1997. The effect of inhomogeneous roughness on radar backscattering from slightly deformed sea ice. Trans. Geosci. Rem. Sens. 35, 147-159.

Eicken, H., Lensu, M., Leppäranta, M., Tucker II, W. B., Gow, A. J. and Salmela, O. 1995. Thickness, structure, and properties of level summer multiyear ice in the Eurasian sector of the Arctic Ocean. J. Geophys. Res. 100(C11), 22,697-22,710.

Flato, G. M. and Hibler, W. D. 1991. An initial numerical investigation of the extent of sea-ice ridging. Ann. Glaciol. 15, 31-36.

Haas, C., Gerland, S., Eicken, H. and Miller, H. 1997. Comparison of sea-ice thickness measurements under summer and winter conditions in the Arctic using a small electromagnetic induction device. Geophysics 62, 749-757.

Haas, C. and Lensu, M. 1997. Sea ice physical properties. In: The expedition Arctic '96 of $R V$ Polarstern (ARK XII) with the Arctic climate system study ( $A C S Y S$ ) (ed. Augstein, E.). Alfred-Wegener-Institut (AWI), Bremerhaven. Rep. Pol. Res. 234, 27-33.

Haas, C., Liu, Q., Martin, T. and Miller, H. 1998a. Investigation of sea-ice thickness and pressure ridge statistics. In: Scientific report to the project: Remote sensing of sea-ice properties and processes FEME. German Federal Ministry of Education, Research and Technology, grant 03PL018B.

Haas, C., Thomas, D., Steffens, M. and Bareiss, J. 1998b. Physical and biological investigations of sea ice. In: The expedition ANTARKTIS-XIV of RV Polarstern in 1997, Report of Leg ANT-XIV/3, Alfred-Wegener-Institut (AWI), Bremerhaven. Rep. Pol. Res. 267, 18-30.

Harder, M. 1996. Dynamics, roughness, and age of Arctic sea ice - numerical investigations with a large-scale model. Rep. Pol. Res. 203. Alfred-Wegener-Institut (AWI), Bremerhaven.

Harder, M. 1997. Roughness, age and drift trajectories of sea ice in large-scale simulations and their use in model verifications. Ann. Glaciol. 25, 237-240. 
Harder, M. and Lemke, P. 1994. Modelling the extent of sea-ice ridging in the Weddell Sea. In: The polar oceans and their role in shaping the global environment (eds. Johannessen, O. M., Muench, R. D. and Overland, J. E.). AGU. Geophys. Mon. 85, 187-197.

Harder, M., Lemke, P. and Hilmer, M. 1998. Simulation of sea-ice transport through Fram Strait: Natural variability and sensitivity to forcing. J. Phys. Oceanogr 103(C3), 5595-5606.

Hibler, W. D. 1979. A dynamic-thermodynamic sea-ice model. J. Phys. Oceanogr. 9, 815-845.

Hibler, W. D. and Zhang, J. 1994. On the effect of ocean circulation on Arctic ice-margin variations. In: The polar oceans and their role in shaping the global environment (eds. Johannessen, O. M., Muench, R. D. and Overland, J. E.). AGU. Geophys. Mon. 85, 383-397.

Hilmer, M., Harder, M. and Lemke, P. 1998. Sea-ice transport through Fram Strait: a highly variable link between Arctic and North Atlantic. Geophys. Res. Lett 25(17), 3359-3362.

Hopkins, M. A. 1994. On the ridging of intact lead ice. J. Geophys. Res. 99(C8), 16,351-16,360.

Hopkins, M. A. and Hibler, W. D. 1991. On the ridging of a thin sheet of lead ice. Ann. Glaciol. 15, 81-86.

Hopkins, M. A., Hibler, W. D. and Flato, G. M. 1991. On the numerical simulation of the sea ice ridging process. J. Geophys. Res. 96(C3), 4809-4820.

Kovacs, A. 1971. On pressured sea ice. In: Sea ice (ed. Karlsson, T.). Reykjavik, Iceland, International Sea Ice Conference, 276-295.

Kreyscher, M. 1998. Dynamics of Arctic sea ice — validation of different rheology schemes for the use in climate models. Rep. Pol. Res. 291. Alfred-Wegener-Institut (AWI), Bremerhaven.

Kreyscher, M., Harder, M. and Lemke, P. 1997. First results of the Sea Ice Model Intercomparison Project (SIMIP). Ann. Glaciol. 25, 8-11.

Lemke, P., Hibler, W. D., Flato, G., Harder, M. and Kreyscher, M. 1997. On the improvements of sea ice models for climate simulations: the Sea Ice Model Intercomparison Project. Ann. Glaciol. 25, 183-187.

Leppäranta, M. 1981. An ice drift model for the Baltic Sea. Tellus 33, 583-596.

Liu, Q., Haas, C., Martin, T. and Augstein, E. 1998. Study of sea-ice pressure ridge distributions from in situ Laser Profiler. In: Proceedings of the European Conference on Synthetic aperture radar. Friedrichshaven, Germany.

McLaren, A. S., Wadhams, P. and Weintraub, R. 1984. The sea-ice topography of M'Clure Strait in winter and summer of 1960 from submarine profiles. Arctic 37, 110-120.

Melling, H. and Riedel, D. A. 1995. The underside topography of sea ice over the continental shelf of the Beaufort Sea in the winter of 1990. J. Geophys. Res. 100(C7), 13,641-13,653.

NSIDC. 1998. National Snow and Ice Data Center. Submarine upward looking sonar ice draft profile data and statistics. Digital data available from nsidc@kryos.colorado.edu. NSIDC, University of Colorado at Boulder.

Omstedt, A. 1998. Freezing estuaries and semi-enclosed basins. In: Physics of ice covered seas, vol. 2 (ed. Leppäranta, M.). Department of Geophysics. University of Helsinki. PO Box 4. FIN-00014 Finland, 483-516.

Omstedt, A. and Svensson, U. 1992. On the melt rate of drifting ice heated from below. Cold Reg. Sci. Techn. 21, 91-100.

Overland, J. E. and Colony, R. L. 1994. Geostrophic drag coefficients for the central Arctic derived from Soviet drifting station data. Tellus 46A, 75-85.

Overland, J. E. and Davidson, K. L. 1992. Geostrophic drag coefficients over sea ice. Tellus 44A, 54-66.

Parkinson, C. L. and Washington, W. M. 1979. A largescale numerical model of sea ice. J. Geophys. Res. 84(C1), 6787-6803.

Parmerter, R. R. and Coon, M. D. 1972. Model of pressure ridge formation in sea ice. J. Geophys. Res. 77(33), 6565-6575.

Raupach, M. R., Gilette, D. A. and Leys, J. F. 1993. The effect of roughness elements on wind erosion threshold. J. Geophys. Res. 98, 3023-3029.

Romanov, I. P. 1995. Atlas of ice and snow of the Arctic Basin and Siberian Shelf Seas (ed. Tunic, A.). Backbone Publishing Company.

Rothrock, D. A. 1975. The energetics of plastic deformation of pack ice by ridging. J. Geophys. Res. 80(33), 4514-4519.

Rothrock, D. A. and Thorndike, A. S. 1980. Geometric properties of the underside of sea ice. J. Geophys. Res. 85(C7), 12,601-12,605.

Squire, V. A. 1998. The marginal ice zone. In: Physics of ice covered seas, vol. 1 (ed. Leppäranta, M.). Department of Geophysics. University of Helsinki. PO Box 4. FIN-00014 Finland, 483-516.

Steele, M., Morison, J. H. and Untersteiner, N. 1989. The partition of air-ice-ocean momentum exchange as a function of ice concentration, floe size and draft. J. Geophys. Res. 94(C9), 12,739-12,750.

Steiner, N. 1999. Sea ice roughness as a means to validate and optimize a large-scale sea ice model for the Arctic. $\mathrm{PhD}$ thesis, Christian-Albrechts-Universität zu Kiel, Institute of Marine Research, 24105 Kiel, Germany.

Steiner, N., Harder, M. and Lemke, P. 1998a. Modelling sea-ice roughness in the Arctic. In: Ice physics and the natural environment (eds. Wettlaufer, J. S., Dash, J. G. and Untersteiner, N.). Springer-Verlag, Heidelberg, vol. I, 341-346.

Steiner, N., Harder, M., Lemke, P. and Schuster, S. 1998b. Modelling sea-ice deformation in the Weddell Sea and in the Arctic. In: Scientific Report to the Project: Remote sensing of sea-ice properties and processes FEME. German Federal Ministry of Education, Research and Technology, Grant 03PL018A.

Thorndike, A. S. 1992. Estimates of sea-ice thickness distribution using observations and theory. J. Geophys. Res. 97(C8), 12,601-12,605.

Thorndike, A. S. and Colony, R. L. 1982. Sea ice motion

Tellus 51A (1999), 5 
in response to geostrophic winds. J. Geophys. Res. 89 , $5845-5852$.

Timco, G. W. and Burden, R. P. 1997. An analysis of the shapes of sea ice ridges. Cold Reg. Sci. Tech. $\mathbf{2 5}$ 65-77.

Tucker, W. B. 1989. An overview of the physical properties of sea ice. In: Proceedings of Workshop on Ice properties. Tech. Memo. 144 (NRCC 30358), 71-85. Assoc. Comm. on Geotech. Res., Natl. Res. Counc. Can.

Wadhams, P. 1980. A comparison of sonar and laser profiles along corresponding tracks in the Arctic Ocean. In: Sea ice processes and models (ed. Pritchard, R. S.). Univ. of Washington Press, Seattle, 283-299. Wadhams, P. 1992. Sea-ice thickness distribution in the Greenland Sea and Eurasian Basin, May 1987. J. Geophys. Res. 97(C4), 5331-5348.

Wadhams, P. 1994. Sea-ice thickness changes and their relation to climate. In: The polar oceans and their role in shaping the global environment (eds. Johannessen, O. M., Muench, R. D. and Overland, J. E.). AGU. Geophys. Mon. 85, 337-361.
Wadhams, P. 1998. Sea ice morphology. In: Physics of ice covered seas, vol. 1 (ed. Leppäranta, M.). Department of Geophysics. University of Helsinki. PO Box 4. FIN-00014 Finland, 483-516.

Wadhams, P. and Horne, J. 1980. An analysis of ice profiles obtained by submarine sonar in the Beaufort Sea. Journal of Glaciology 25, 401-424.

Weeks, W. F., Kovacs, A. and Hibler, W. D. 1971. Pressure ridge characteristics in the Arctic coastal environment. In: Proceedings of the 1st International Conference on Port and ocean engineering under arctic conditions (eds. Wetteland, S. S. and Bruun, P.) Technical University of Norway, Trondheim, vol. 1, 152-183.

Wittmann, W. I. and Schule, J. J. 1966. Comments on the mass budget of Arctic pack ice. In: Proceedings of the symposium on the arctic heat budget and atmospheric circulation (ed. Fletcher, J. O.). Rand Corp. Santa Monica, California, vol. RM-5237-NSF, 215-246. 